\title{
Group-based education for people with type 2 diabetes mellitus in Greece: An observational study
}

\author{
Kyriakoula Merakou ${ }^{* 1}$, Argyro Knithaki ${ }^{2}$, Georgios Karageorgos ${ }^{1}$, Dimitrios Theodoridis ${ }^{1}$, Anastasia Barbouni ${ }^{1}$ \\ ${ }^{1}$ Department of Public and Administrative Health, National School of Public Health, Athens, Greece \\ ${ }^{2}$ Health Center of Markopoulo, Attica, Greece
}

Received: November 16, 2014

DOI: $10.5430 /$ jnep.v5n5p118
Accepted: January 28, $2015 \quad$ Online Published: March 19, 2015

URL: http://dx.doi.org/10.5430/jnep.v5n5p118

\begin{abstract}
Objective: The objective of this study is the assessment of the impact of a brief patient group education intervention (Conversation Maps $^{\mathrm{TM}}$ ) in people with type 2 Diabetes Mellitus.

Methods: A total of 138 people with type 2 Diabetes Mellitus who were regular patients at the diabetic clinic of a Primary Health Care setting in Attica participated in the study. The intervention group attended a structured group, brief educational programme (three sessions of two hours each). The main outcome measures were glycated hemoglobin (HbA1c), Body Mass Index (BMI), triglycerides, High-density lipoprotein (HDL), Low-density lipoprotein (LDL), measured at baseline and six months after the intervention.

Results: After 6 months, significant reductions were observed between the baseline and follow-up data in HbA1c $(p<.001)$ in BMI $(p<.007)$ in triglycerides $(p<.003)$, in LDL-cholesterol $(p<.001)$, while the mean HDL-cholesterol remained stable $(p=$ .397).

Conclusions: Group-based patient education with Conversation Maps ${ }^{\mathrm{TM}}$ for people with type 2 diabetes is effective in the improvement of clinical outcomes.
\end{abstract}

Key Words: Group patient education, Type 2 diabetes mellitus, HbA1c, BMI, Lipidemic profile

\section{INTRODUCTION}

Diabetes Mellitus is one of the most costly chronic diseases worldwide. 382 million people suffered from diabetes in 2013 and this number is expected to rise to 592 million by 2035, while 175 million people remain undiagnosed. Ninety percent of these people suffer from type 2 Diabetes Mellitus (DM). ${ }^{[1]}$ In Europe, the number of people suffering from type 2 DM was estimated at 52.8 million in 2011 and 64.2 million in $2030^{[1]}$ while 196 million USD were spent on health care in 2010, an amount that is projected to rise to approximately 235 US dollars in 2030. ${ }^{[2]}$
In Greece, a significantly higher prevalence rate has been recorded for type $2 \mathrm{DM}$ (from $2.8 \%$ in 1970 to $7.6 \%$ in 2002). ${ }^{[3]}$ Moreover, there is an additional 3\%-4\% of the population who are unaware that they suffer from the disease. ${ }^{[4]}$ Furthermore, the annual cost for type 2 DM exceeds the amount of 1 billion euro (1.011.890.880 euro), representing $5.2 \%$ of the total current expenditure for health while the average annual patient cost for type $2 \mathrm{DM}$ was 1297.30 euro (95\% CI, 1244.42-1349.61 euro). In addition to this, non-controlled patients had $29.7 \%$ higher annual pharmaceutical costs, $70 \%$ higher costs for laboratory/diagnostic tests and $85.5 \%$ higher consultation costs compared with their

*Correspondence: Kyriakoula Merakou; Email: kmerakou@esdy.edu.gr; Address: Dept. of Public and Administrative Health, National School of Public Health, Athens, 11521, Greece. 
controlled peers. ${ }^{[5]}$

Patient education constitutes a critical tool used to better control diabetes, to help prevent complications and reduce the costs. ${ }^{[6]}$ There is no adequate evidence of which education methods are the most effective in improving the clinical outcomes of people with type 2 diabetes. Group education has been characterized as a cost-effective alternative to individual education for diabetes. ${ }^{[7]}$ Several studies point out that diabetes group education, compared to individual education, was equally effective at improving diabetes control. ${ }^{[6,8,9]} \mathrm{A}$ review of eleven studies points out that group-based education for people with type $2 \mathrm{DM}$ has been shown effective in improving $\mathrm{HbA} 1 \mathrm{c}$, diabetes knowledge, the reduction of systolic blood pressure levels, body weight, and the requirement for diabetes medication. ${ }^{[10]}$ Moreover, a recent systematic review with meta-analysis of 21 studies showed that group education had significant changes, compared to individual education in HbA1c in 6 months $(p=.001)$, in 12 months $(p=.001)$ and in two years $(p=.000){ }^{[11]}$ However, a recent study, using group based Conversation Map sessions for educating people with type 2 diabetes, pointed out that individual education resulted in better glucose control outcomes than group education. ${ }^{[12]}$ In Greece, existing evidence in assessing the effectiveness of diabetes self-management education, especially group based education, is sparse and new studies are needed. The present study evaluates the effectiveness of group education for people with type $2 \mathrm{DM}$ in a primary health care centre. Specific objectives of the study include evaluation of:

- The changes in glycated hemoglobin (HbA1c),

- The changes in Body Mass Index (BMI),

- The changes in the lipidemic profile (triglycerides, High-density lipoprotein [HDL], Low-density lipoprotein [LDL]))

The main hypothesis of this study was whether group education would improve biochemical markers (HbA1c, BMI, triglycerides, LDL, HDL).

\section{MATERIAL AND METHODS}

\subsection{Participants}

The present study was conducted in the Health Centre of the Primary Health Care Clinic in the City of Markopoulo, $25 \mathrm{~km}$ outside Athens, the capital of Greece. People with type $2 \mathrm{DM}$ who have been regular patients of the physicians at the Health Centre participated in the study. The eligibility criteria included: people diagnosed with type $2 \mathrm{DM}$, living in the region, aged 18 and over, who did not suffer from hypertension or other serious diseases (heart, stroke, kidney or mental disease), did not take insulin, had not developed any

Published by Sciedu Press complications, spoke and comprehended the Greek language sufficiently and were willing to participate. All people with type 2 DM who were regular patients at the Diabetic Outpatient Clinic at the Health Centre were eligible to participate in the study.

\subsection{Randomization}

Random sampling was used during the period 2-18 May 2012. Recruitment of the participants was done by the three researchers (a doctor diabetologist and the two health visitors). The eligibility criteria for researchers performing the intervention were: to be permanent employees of the Health Centre, to work in the Diabetic Outpatient Clinic, to be one doctor specialized in diabetes and two health visitors who facilitated group education. All patients who were registered on the outpatient list at the diabetic clinic were eligible to participate in the study. For every four names/appointments, the first 3 individuals were selected for the study group and the fourth was excluded because he/she was selected to participate in another study carried out at the same time. Figure 1 shows the CONSORT (Consolidated Standards of Reporting Trials) flow diagram.

One hundred and sixty five people were selected to participate in the study. Twenty seven out of the 165 participants were not included in the study either because they were on insulin therapy or suffered from serious diseases (16 people) or because they did not agree to attend the educational programme (11 people). Finally, 138 people participated in the study group.

\subsection{Patient educational intervention}

The intervention group participants were divided into 19 groups (3-8 people per group). Each group attended a 6hour educational programme, two hours per week each, and spread, in three sessions, over a period of 3 weeks. The education for all groups lasted from May to September 2012. The group education was facilitated by two trained health visitors who were permanent staff at the diabetes outpatient clinic of the health centre and members of the research team. Health visitors in Greece are 4-year college graduates studying nursing, community health and health education and promotion. In the present study, health visitors conducted group education, and the follow up process. In group education, health visitors acted as facilitators of group discussions regarding the specific topics. The educational techniques they used included brain storming, group discussion, questions and answers, scenario analysis. The research protocol was assessed by the Director of the Health Centre.

The educational material consisted of "Conversation Maps ${ }^{\text {TM}}$ : Learning about Diabetes" which are interactive 
tools that include pictures and cards with topics for discussion, providing everyone with the opportunity to participate in the education process. This material is the product of a three-year international collaboration between the Pharma- ceutical Company Lilly and the company Healthy Interactions that works worldwide on health education, as well as the European Branch of the International Diabetes Federation (IDF). ${ }^{[13]}$

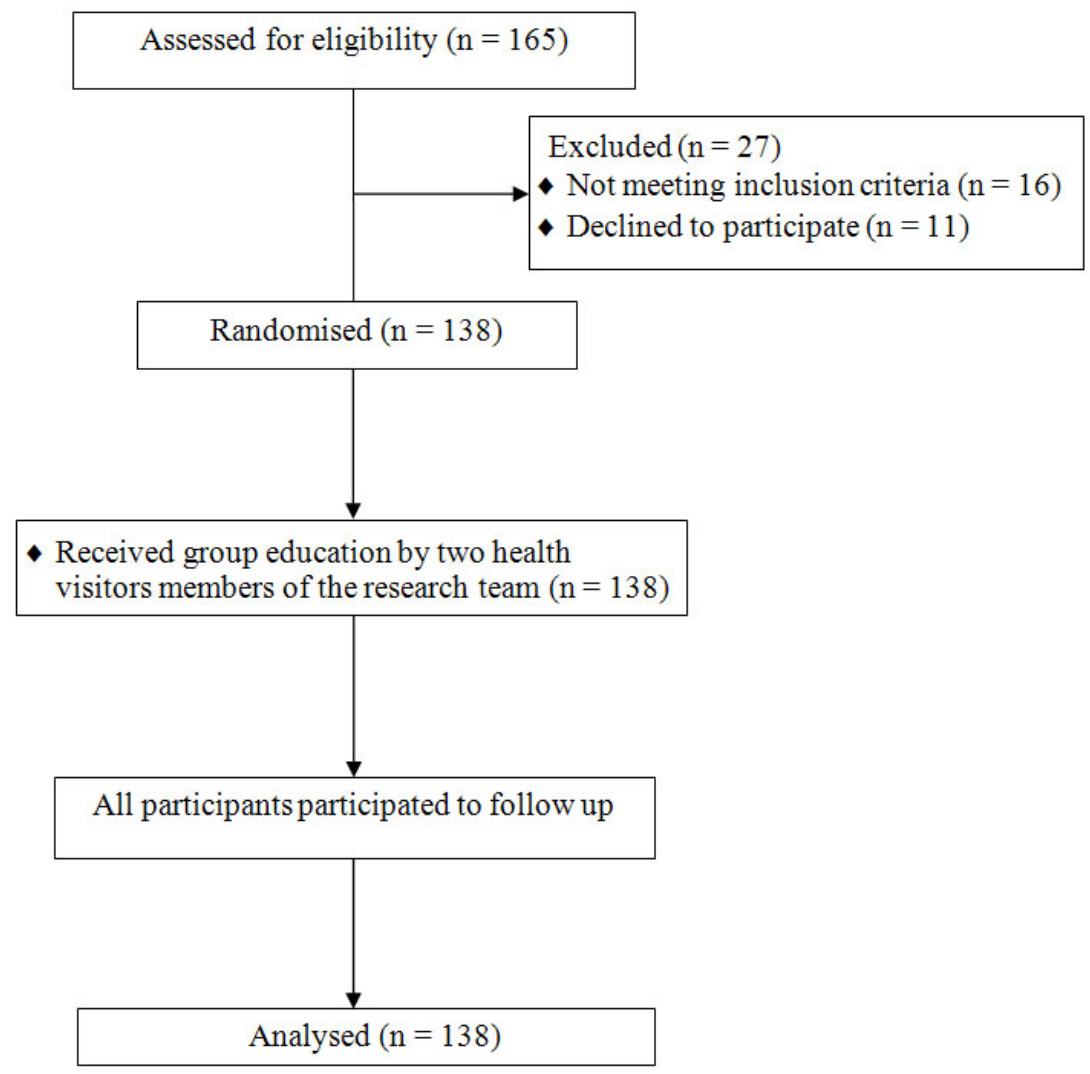

Figure 1. Flow diagram

The educational material consists of 4 visual maps (Conversation Maps ${ }^{\mathrm{TM}}$ ) sized $91.44 \mathrm{~cm} \times 152.4 \mathrm{~cm}$ which have been designed for use by small teams of between 3 and 10 people. Conversation maps cover four issues about diabetes such as:

(1) “Living with Diabetes" which constitutes a review of diabetes and includes a description of what the disease is as well as some of the most widely spread myths about diabetes.

(2) "How diabetes works" gives the participants the opportunity to discuss in depth the pathophysiology of diabetes.

(3) "Healthy diet and physical exercise" which focuses on the changes the patients should make to their lifestyle in order to gain a better quality of life and avoid or slow down potential complications.

(4) "Insulin therapy initiation" covers basic issues about initiating insulin therapy, including the reasons behind the necessity of insulin for people with Type 2 DM.
This map was not used in the present study because the participants were not dependent on insulin use.

\subsection{Outcomes}

Recordings were taken at baseline - before the start of the programme - and 6 months after its completion (follow-up), during the patients' scheduled appointment.

\subsubsection{Biochemical markers}

- HbA1c (mmol/mol). Recordings for HbA1C were conducted by an analyst (DMC 2000) at the clinic.

- Triglycerides $(\mathrm{mmol} / \mathrm{L})$

- HDL-cholesterol (mmol/L)

- LDL-cholesterol (mmol/L)

\subsubsection{Anthropometry}

BMI is calculated by dividing the weight $(\mathrm{kg})$ with the square of the height $\left(\mathrm{m}^{2}\right)$ and is used as an assessment indicator for obesity. Body weight and height of the participants were 
measured with digital scales (Seca) and with an integrated measuring rod.

\subsubsection{Ethical dimensions of the study}

Participants were asked to provide their written consent after they had been informed about the educational programme and the study. Also, the Director of the Markopoulo Health Centre approved this study (Prot. No.1712/2012).

\subsection{Statistical methods}

Average values (mean) and standard deviations (SD) were used to describe the continuous variables. Absolute $(\mathrm{N})$ and relative $(\%)$ frequencies were used for the description of categorical variables. For the comparison of proportions chi-square and Fisher's exact tests were used. Differences in changes of study variables during the follow up period between the two study groups were evaluated using repeated measurements analysis of variance (ANOVA). All reported $p$ values are two-tailed. Statistical significance was set at $p<.05$ and analyses were conducted using SPSS statistical software (version 17.0).

\section{RESULTS}

The sample consisted of 138 people. Demographic data and baseline clinical recordings are presented in Table 1 .

\subsection{HbA1c}

HbA1c values of the participants decreased significantly after the intervention, with an average change value of $-0.6 \pm 1.1$ $(p<.001)$ (see Table 2). Additionally, six months after the intervention, the increase in the percentage of people with $\mathrm{HbA} 1 \mathrm{c}<7 \mathrm{mmol} / \mathrm{mol}$ was statistically significant $(\mathrm{N}=27$, $28.7 \%$ before and $\mathrm{N}=4,3.8 \%$ after $)(p<.001)$. HbA1c values were significantly higher at baseline for the participants aged 69 or younger in comparison with the participants whose age was 69 or older $(p=.030)$. After six months, there was a statistically significant decrease in the HbA1c values, irrespective of the demographic data of the group apart from age $(p=.014)$. When multiple linear regression was conducted it was found that participants older than 69 years had a 0.49 units smaller change (decrease) in the HbA1c values after the 6-month period $(\beta=-0.49, \mathrm{SE}=0.23, p=.037)$.

Table 1. Demographic data and risk factors of the study group

\begin{tabular}{|c|c|c|c|}
\hline & \multicolumn{2}{|c|}{ Study Group } \\
\hline & & $\mathbf{N}$ & $\%$ \\
\hline \multicolumn{2}{|c|}{ Age $($ Mean \pm SD) } & \multicolumn{2}{|c|}{$67.2 \pm 10.7$} \\
\hline \multirow{2}{*}{ Sex } & Men & 74 & 53.6 \\
\hline & Women & 64 & 46.4 \\
\hline \multirow{2}{*}{$\begin{array}{l}\text { Educational } \\
\text { level }\end{array}$} & Primary/high school & 113 & 81.9 \\
\hline & $\begin{array}{l}\text { Secondary/College/ } \\
\text { University }\end{array}$ & 25 & 18.1 \\
\hline \multirow{3}{*}{ Smoking } & No & 38 & 29.9 \\
\hline & Yes & 51 & 40.2 \\
\hline & In the past & 38 & 29.9 \\
\hline \multicolumn{2}{|c|}{ Years suffering from DM2 (Mean \pm SD) } & \multicolumn{2}{|c|}{$7.7 \pm 5.4$} \\
\hline \multicolumn{2}{|c|}{ BMI (Mean \pm SD) } & \multicolumn{2}{|c|}{$32.4 \pm 5.5$} \\
\hline \multirow{3}{*}{ BMI } & Normal & 6 & 6.3 \\
\hline & Overweight & 29 & 30.5 \\
\hline & Obese & 60 & 63.2 \\
\hline \multirow{2}{*}{ Obese } & No & 35 & 36.8 \\
\hline & Yes & 60 & 63.2 \\
\hline \multicolumn{2}{|c|}{$\mathrm{HbA} 1 \mathrm{c}($ Mean $\pm \mathrm{SD})(\mathrm{mmol} / \mathrm{mol})$} & \multicolumn{2}{|c|}{$6.9 \pm 1.3$} \\
\hline $\mathrm{HbA1c}$ & $<7$ & 67 & 71.3 \\
\hline$(\mathrm{mmol} / \mathrm{mol})$ & $\geq 7$ & 27 & 28.7 \\
\hline \multicolumn{2}{|c|}{ Triglycerides (Mean $\pm \mathrm{SD})(\mathrm{mmol} / \mathrm{L})$} & \multicolumn{2}{|c|}{$167.7 \pm 99.9$} \\
\hline \multicolumn{2}{|c|}{ HDL (Mean \pm SD) (mmol/L) } & \multicolumn{2}{|c|}{$47.3 \pm 11.9$} \\
\hline \multicolumn{2}{|c|}{ LDL $($ Mean \pm SD) $(\mathrm{mmol} / \mathrm{L})$} & \multicolumn{2}{|c|}{$123.8 \pm 40.1$} \\
\hline
\end{tabular}

Table 2. Risk factors changes (HbA1c, BMI, Tryglycerides, HDL and LDL) for participants before and 6 months after the intervention

\begin{tabular}{|c|c|c|c|c|c|c|}
\hline & \multicolumn{2}{|c|}{ Before intervention } & \multicolumn{2}{|c|}{6 months after intervention } & \multirow{2}{*}{$\begin{array}{l}\text { Change } \\
\text { Mean } \pm \text { SD }\end{array}$} & \multirow{2}{*}{$\mathbf{P}^{* *}$} \\
\hline & Mean \pm SD & Median (IQR) & Mean \pm SD & Median (IQR) & & \\
\hline HbA1c (\%) (mmol/mol) & & & & & & \\
\hline Study group & $6.9 \pm 1.3$ & $6.5(6.1-7.1)$ & $6.3 \pm 0.6$ & $6.3(6.0-6.6)$ & $-0.6 \pm 1.1$ & $<.001$ \\
\hline $\begin{array}{l}\text { BMI } \\
\text { Study group }\end{array}$ & $32.4 \pm 5.5$ & $31.6(28.6-35.1)$ & $31.7 \pm 5.5$ & $31.1(27.8-34.6)$ & $-0.7 \pm 1.8$ & .007 \\
\hline $\begin{array}{l}\text { Triglycerides }(\mathbf{m m o l} / \mathbf{L}) \\
\text { Study group }\end{array}$ & $167.7 \pm 99.9$ & $150(107-204)$ & $146.6 \pm 79.1$ & $126(101-169)$ & $-21.1 \pm 89$ & .003 \\
\hline $\begin{array}{l}\text { HDL }(\mathbf{m m o l} / \mathbf{L}) \\
\text { Study group }\end{array}$ & $47.3 \pm 11.9$ & $46.0(40.0-51.0)$ & $47.2 \pm 11.4$ & $45.0(39.0-55.0)$ & $-0.1 \pm 9.0$ & .397 \\
\hline $\begin{array}{l}\text { LDL }(\mathbf{m m o l} / \mathbf{L}) \\
\text { Study group }\end{array}$ & $123.8 \pm 40.1$ & $122(96-152)$ & $113.8 \pm 31.7$ & $110(93-132)$ & $-10.0 \pm 40.0$ & .001 \\
\hline
\end{tabular}

** Difference between recordings 


\subsection{BMI}

In the intervention group participants' BMI decreased significantly after the intervention with an average change value of $-0.7 \pm 1.8(p=.007)$ (see Table 2). This significant decrease in the participants' BMI was observed in men $(p=.010)$, in university/college/secondary school graduates $(p=.001)$, in the participants with a diagnosis of less than 6 years $(p=$ $.016)$ and was independent of their age (for those aged 69 or older $p=.049$, and in those aged 69 or younger $p=.050$ ).

\subsection{Lipidemic profile}

A statistically significant decrease of the triglycerides value was presented especially in people under 69 years of age $(p=.011)$, in men $(p=.009)$, in those who had completed primary education/high school $(p=.010)$ as well as in those people who had been living with type $2 \mathrm{DM}$ for less than 6 years $(p=.009)$ (see Table 2).

In HDL values no significant change was observed $(p=.397)$ (see Table 2). The participants who were aged 69 or over had significantly higher HDL values, before as well as 6 months after the intervention, in comparison with the participants of younger ages ( $p=.046$ and $p=.012$ respectively). Additionally, women had significantly higher HDL values, before as well as 6 months after the intervention ( $p=.004$ and $p=.004$ respectively).

Additionally, according to Table 2, there was a significant reduction in LDL values 6 months after the intervention (-10 $\pm 40)(p=.001)$. Six months after the educational intervention, higher LDL values were recorded for the participants who were older than 69 years of age $(p=.002)$, for people that had completed primary education/high school $(p<.001)$, and were irrespective of sex (for men $p=.020$ and women $p$ $=.029$ ) and years of diagnosis (for those living with diabetes less than 6 years $p=.022$, and for those living with diabetes more than 6 years $p=.024)$. More precisely, there was a significant reduction in the participants who had completed primary education/high school while in the participants who had acquired higher education there was no significant change. According to multivariate linear regression analysis, educational level was found to correlate independently and predict changes in LDL; those participants who had completed secondary school/technical school/university had $28,23 \mathrm{mmol} / \mathrm{L}$ lower change (decrease) in LDL compared to the participants who had completed primary education/high school ( $\beta$ $=-28.23, \mathrm{SE}=11.66, p=.018$ ).

\section{Discussion}

The findings of this study indicate that a short group educational programme with the use of the Conversation Maps ${ }^{\mathrm{TM}}$ «Learning about Diabetes» may improve HbA1c, BMI and the lipidemic profile of people with type 2 DM. Participants in the study group improved almost all parameters that were measured (HbA1c, BMI, triglycerides, and LDL).

\subsection{HbA1c}

Improvements in $\mathrm{HbA} 1 \mathrm{c}$ were significant. It is worth mentioning that the study group had lower HbAlc levels before the intervention which means that there was, perhaps, little room for improvement. However, this observation cannot be attributed to the educational procedure due to the limited size of the study. Our findings coincide with the results of other randomized studies, in which educational interventions were associated with drops in A1c levels by $0.76 \%$ on average $^{[9]}$ or, based on a meta-analysis, by a mean of $0.43 \% .{ }^{[10]}$ Glycemic control improvement after attending an educational programme has also been shown by other investigators who have, however, followed different methodologies of health promotion. $^{[11-13]}$

The time spent with the instructor appears to affect A1c reduction. Norris et al. ${ }^{[9]}$ report that in order to achieve a reduction of $1 \%$ for A1c, 23.6 hours are required to be spent with the instructor. In our study, the time spent with the instructor was only 6 hours, however, the instructor was a member of the staff of the Health Clinic Centre and patients were not recently diagnosed.

After the 6 month period, reduction in HbA1c in the study group was significantly higher in participants up to 69 years of age in comparison to older patients. Age has been considered as a factor that influences the effectiveness of health promotion programmes for diabetes. The younger the age of a patient, the better it is to achieve diabetes control after attendance at educational programs. ${ }^{[14,15]}$ Possible explanations for this observation include older patients' inability to sufficiently follow the variety of subjects of such educational programmes for type $2 \mathrm{DM}$ due to impaired vision, inability to hear or remember well enough, as well as due to potential diabetes complications. ${ }^{[15]}$

\subsection{BMI}

According to the results of the present study, there was a statistically significant reduction in BMI of the participants. On the contrary, in a study on the effectiveness of health education and promotion programmes based on changing the BMI in patients with type 2 DM, Salinero-Fort et al. (2011) reported that there was no statistically significant reduction in BMI between the two study groups (intervention and control). The authors attributed their findings to the fact that both groups devoted the same amount of time to physical exercise. ${ }^{[16]}$ Moreover, this finding is in contrast with findings from other studies that there was no significant difference 
between individual and group education in the reduction of BMI at 6 to 9 months ${ }^{[17]}$ or at 12 to 18 months. ${ }^{[18,19]}$

Age was independent of BMI change, a finding meaning that the participants were influenced by the educational program independently of their age. A possible explanation for this is that maybe retirement, leisure time, similar life conditions, and similar age (mean age was $67 \pm 10.7$ ) helped all participants to decrease their BMI. Moreover, the semi-urban are they lived in provided participants with the chance of incorporating the knowledge and messages of the educational program more easily in their everyday life, especially for physical activity.

\subsection{Lipidemic profile}

According to the results of our study, the lipidemic profile was improved within 6 months of the completion of the educational programme. More precisely, triglycerides and LDL decreased significantly while HDL remained stable. Similar results have been reported in other studies which evaluated the effectiveness of educational intervention in the primary health care setting in people with type $2 \mathrm{DM}$, that is, when patient education is conducted either individually or in a group, patients' lipidemic profile improves. ${ }^{[20,21]}$

Variable correlations of the lipidemic indicators in relation to the demographic data of our participants indicated that the degree of decrease of LDL-cholesterol in the intervention group correlated independently with the educational level of the participants. More precisely, there was a significant reduction in LDL-cholesterol for primary education/high school graduates (6-9 years of school) while for secondary school/university graduates (12-16 years of studying) there was no significant change. A possible explanation for this is that provision of picture and discussion educational tools are very important for people with a low educational level. Despite the fact that our research group was surprised with this result, another research in Oman confirmed this finding; in a health promotion programme focusing on diet and lifestyle in people with type $2 \mathrm{DM}$, compliance of the participants who had a low educational level was better as was their lipidemic profile. ${ }^{[22]}$ Moreover, our finding coincides with the results of a review by Pignone et al. ${ }^{[23]}$ as it was shown that people with a low educational level may benefit more from health education programmes than those with a higher education, if those programmes are organized in such a way as to facilitate incorporation of self care into every-day life. Other authors support that introduction of structural changes in the way health care is provided (e.g., Conversation Maps ${ }^{\mathrm{TM}}$ ) may generate valuable benefits for patients with a low educational level. ${ }^{[24]}$ Moreover, a meta-analysis of five studies on the relationship between the educational level and the benefits

Published by Sciedu Press derived from educational interventions revealed that half of these studies proved that patients with a low educational level benefited to a greater degree and the remaining half to a lesser degree, although the authors attributed these differences to the quality of the research (e.g., in the use of a different rating scale). ${ }^{[25]}$

Gender was not identified as an independent demographic factor in our study. From statistical analysis between educational level and gender no relation revealed. According, to the Hellenic Statistical Authority, in 1991 census, about the same percentage of men and women aged 25-64 years had completed primary and secondary education level (12 school years); however, 69 women to 100 men complete college or university. ${ }^{[26]}$ In our sample the participants of both sexes belonged to the above group age at that year of census and received similar school education. Moreover, the great majority of the participants (men and women) had completed primary and secondary educational level while more men than women were included in the sample.

According to our findings, group educational intervention constitutes an effective method in the primary health care setting in order to improve glycemic control, reduce BMI and improve the lipidemic profile. In explaining these findings we should take into consideration that these specific patients were already being monitored at the primary health care setting, knew the staff and lived in the area and as a result may have been positively predisposed to change their behavior. Additionally, the educational material was colorful and large in size which may have helped people to better comprehend their disease. Moreover, people' conversations with the instructor and the other participants, as well as being able to discuss their own experiences with diabetes, may constitute powerful advantages of group education. ${ }^{[24]}$

\subsection{Limitations}

The present study has a number of limitations. The study focused on the short-term effects of a behavioral change over a 6 month period. Longer monitoring periods of 12 or 24 months would provide more information on the long-term effects of group educational interventions. Additionally, the study sample is not representative of the general population of Greece for people with type $2 \mathrm{DM}$ and, as a result, it is not possible to generalize the conclusions reached in this study; however, it could be representative for people with type 2 DM, living at the same area, who visit the health center. This research should be replicated in different health or community settings to examine the effectiveness of group patient education with type 2 DM. Additionally, other success factors of the programme such as the excellent size of the group, the economic evaluation of group education in comparison to 
standard care, as well as the efficiency assessment in relation to the resources available (money, personnel, etc.) were not investigated. Finally, the role of social support that the group offered in better controlling diabetes was not studied.

\subsection{Implications}

Our findings show that diabetes is well regulated in patients who attended group education. Methods and techniques of patients' education constitute an important part of effectiveness. Health professionals in the primary health care sector should be trained to effectively coordinate groups of patients. Perhaps the most cost-saving way of implementing educational and health promotion programmes for people with type $2 \mathrm{DM}$ in Greece is the use of the already existing primary health care structures, together with the development of the existing health care personnel. Implementation, maintenance and expansion of such programmes in the health care sector could constitute one of the most significant structural changes.

\section{Conclusions}

The findings of this study show that a short educational programme in a group using the Conversation Maps " ${ }^{\mathrm{TM}}$ "Learning about Diabetes" may be more effective in regulating metabolic control in people with type $2 \mathrm{DM}$, as almost all the measured parameters (HbA1c, BMI, triglycerides, and LDL) were improved. Introducing group education to patients with type 2 DM could improve patients' metabolic regulation and clinical outcomes.

\section{CONFlicts OF InTEREST Disclosure}

The authors declare that there is no conflict of interest statement.

\section{REFERENCES}

[1] International Diabetes Federation. IDF Diabetes Atlas, 6th edition. November 2013. Last accessed 17 December 2013. Available from: http://www.idf.org/diabetesatlas/introduction

[2] International Diabetes Federation. Economic impact of Diabetes. Last accessed 17 December 2013. Available from: http://www.id f.org/sites/default/files/Economic_impact

[3] Panagiotakos DB, Pitsavos C, Chrysohoou C, et al. The association between adherence to the Mediterranean diet and fasting incidences of glucose homeostasis: the ATTICA Study. Journal of American College of Nutrition. 2007; 26(1): 32-8. http://dx. doi .org/10 1080/07315724.2007.10719583

[4] Hellenic Diabetes Association, World Day of Diabetes. November 2012. Last accessed 12 December 2013. Available from: http: //www.ede.gr/wp-content/uploads/2012/11/

[5] Liatis S, Thomakos P, Papaoikonomou S, et al. Trends in the management of type 2 diabetes and its prescription drug costs in Greece (1998 \& 2006). Experimental and Clinical Endocrinology and Diabetes. 2009; 117(9): 505-10. PMid:19629932 http://dx.doi .org /10.1055/s-0029-1225338

[6] Athanasakis K, Ollandezos M, Angeli A, et al. Estimating the direct cost of Type 2 diabetes in Greece: the effects of blood glucose regulation on patient cost. Diabetic Medicine. 2010; 27(6): 679-84. PMid:20546287 http://dx.doi.org/10.1111/j.146 4-5491.2010.03004.x

[7] Rickheim PL, Weaver TW, Flader JL, et al. Assessment of Group Versus Individual Diabetes Education: A randomized study. Diabetes Care. 2002; 25(2): 269-274. http://dx.doi.org/10.2337/dia care.25.2.269

[8] Healthy Interactions. Conversation Maps TM Programs. 2009. Last accessed 23 July 2013. Available from: http: //www . healthyint eractions.com/conversation-mapprograms/conversatio n-map-experience/current-programs/usdiabetes

[9] Norris SL, Engelgau MM, Narayan KM. Effectiveness of selfmanagement training in type 2 diabetes: a systematic review of randomized controlled trials. Diabetes Care. 2002; 24(3): 561-87. http://dx.doi.org/10.2337/diacare.24.3.561
[10] Gary TL, Genkinger JM, Guallar E, et al. Meta-analysis of randomized educational and behavioral interventions in type 2 diabetes. Diabetes Education. 2003; 29(3): 488-501. http://dx.doi.org $/ 10.1177 / 014572170302900313$

[11] Duke SA, Colagiuri S, Colagiuri R. Individual patient education for people with type 2 diabetes mellitus. Cochrane Database Syst Rev. 2009; CD005268. PMid:19160249

[12] Abdo NM, Mohamed ME. Effectiveness of health education program for type 2 diabetes mellitus patients attending Zigazig University Diabetes Clinic, Egypt. Journal of Egyptian Puplic Health Association. 2010; 85(3, 4): 113-130.

[13] Trento M, Passera P, Borgo E, et al. A 5-year randomized controlled study of learning, problem solving ability, and quality of life modifications in people with type 2 diabetes managed by group care. Diabetes Care. 2004; 27(3): 670-75. http://dx.doi.org/10.23 37/diacare.27.3.670

[14] McPherson ML, Smith SW, Powers A, et al. Association between diabetes patients' knowledge about medications and their blood glucose control. Research in Social \& Administrative Pharmacy. 2008; 4(1): 37-45. PMid:18342821 http://dx.doi.org/10.1016/j.s apharm.2007.01.002

[15] Braun A, Sämann A, Kubiak T, et al. Effects of metabolic control, patient education and initiation of insulin therapy on the quality of life of patients with type 2 diabetes mellitus. Patient Education Counselling. 2008; 73(1): 50-9. PMid:18583087 http: //dx.doi.org/10.1016/j.pec.2008.05.005

[16] Salinero-Fort MA, Carrillo-de Santa Pau E, Arrieta-Blanco FJ, et al. Effectiveness of PRECEDE model for health education on changes and level of control of $\mathrm{HbAlc}$, blood pressure, lipids, and body mass index in patients with type 2 diabetes mellitus. BMC Public Health. 2011; 11: 267. PMid:21524316 http://dx.doi .org/10.1186/1 471-2458-11-267

[17] Campbell L, Rössner S. Management of obesity in patients with Type 2 diabetes. Diabetic Medicine. 2001; 18 (5): 345-54. http: //dx.doi.org/10.1046/j.1464-5491.2001.00546.x

[18] Dalmau Llorca MR, García Bernal G, Aguilar Mrtín C, et al. Group versus individual education for type- 2 diabetes patients. Atencion 
Primaria. 2003; 32(1): 36-41. http://dx.doi.org/10.1016/S 0212-6567(03) 78854-4

[19] Valinsky L, Mishali M, Endevelt R, et al. Reducing resistance to treatment, through group intervention, improves clinical measurements in patients with type 2 diabetes. BMC Endocrine Disorders. 2013; 13(1): 61. PMid:24373686 http://dx.doi.org/10.1186 /1472-6823-13-61

[20] Cabrera-Pivaral CE, González-Pérez G, Vega-López MG, et al. Effects of an educational intervention on plasma levels of LDL cholesterol in type 2 diabetics. Salud Publica de Mexico. 2001; 43(6): 55662. PMid:11816230 http://dx.doi.org/10.1590/S0036-363 42001000600006

[21] Mollaoğlu M, Beyazit E. Influence of diabetic education on patient metabolic control. Applied Nursing Research. 2009; 22(3): 18390. PMid:19616166 http://dx.doi .org/10.1016/j . apnr. 20 07.12 .003
[22] Al-Sinani M, Min Y, Ghebremeskel K, et al. Effectiveness of and Adherence to Dietary and Lifestyle Counse Effect on metabolic control in type 2 diabetic Omani patients. Sultan Qaboos University Medical Journal. 2010; 10(3): 341-349. PMid:21509254

[23] Pignone M. Primary prevention: dyslipidaemia. Clinical Evidence. 2005; 14: 142-50. PMid:16620402

[24] Rothman R, Malone R, Bryant B, et al. Pharmacist-led, primary carebased disease management improves hemoglobin A1c in high-risk patients with diabetes. American Journal of Medical Quality. 2003; 18(2): 51-8. http://dx.doi.org/10.1177/106286060301800 202

[25] Brown SA. Meta-analysis of diabetes patient education research: Variations in intervention effects across studies. Research in Nursing \& Health. 2007; 15(6): 409-419. http://dx.doi.org/10.1002 /nur.4770150603

[26] Hellenic Statistical Authority. Educational level of Population. last accessed 4 February 2015. 